(C) The Author(s), 2021. Published by Cambridge University Press. This is an Open Access article, distributed under the terms of the Creative Commons Attribution licence (http://creativecommons.org/licenses/by/4.0/), which permits unrestricted re-use, distribution, and reproduction in any medium, provided the original work is properly cited. 0361-6843/21

\title{
CASTING THE LIGHT OF THE THEORY OF OPPOSITION ONTO HOHFELD'S FUNDAMENTAL LEGAL CONCEPTS
}

\author{
João Alberto de Oliveira Lima (1D
}

Federal Senate, Prodasen, and Instituto Legislativo Brasileiro, Brasília, Brazil; Fiocruz, Brasília, Brazil

\section{Cristine Griffo}

Free University of Bozen-Bolzano, Facoltà di

Scienze e Tecnologie Informatiche, Bolzano, Italy

João Paulo A. Almeida (i)

Federal University of Espírito Santo, Departamento de Informática, Vitória, Brazil

Giancarlo Guizzardi (iD

Free University of Bozen-Bolzano, Facoltà di

Scienze e Tecnologie Informatiche, Bolzano, Italy;

University of Twente, Services and Cybersecurity

Group, Enschede, The Netherlands

Marcio lorio Aranha* (D)

University of Brasilia, School of Law, Brasília, Brazil

\begin{abstract}
At the core of Hohfeld's contribution to legal theory is a conceptual framework for the analysis of the legal positions occupied by agents in intersubjective legal relations. Hohfeld presented a system of eight "fundamental" concepts relying on notions of

\footnotetext{
* Our thanks to David Pardo, Lauro César Araujo, and Flávio Roberto de Almeida Heringer for their comments on an early version of this article. We would like to thank the SUSLegis Project (PRODISA/Fiocruz) for supporting the open access publication. We are grateful to the anonymous reviewers for their constructive input.
} 
opposition and correlation. Throughout the years, a number of authors have followed Hohfeld in applying the notion of opposition to analyze legal concepts. Many of these authors have accounted for Hohfeld's theory in direct analogy with the standard deontic hexagon. This paper reviews some of these accounts and extends them employing recent developments from opposition theory. In particular, we are able to extend application of opposition theory to an open conception of the law. We also account for the implications of abandoning the assumption of conflict-freedom and admitting seemingly conflicting legal positions. This enables a fuller analysis of Hohfeld's conceptual analytical framework. We also offer a novel analysis of Hohfeld's power positions.

\section{INTRODUCTION}

In recent decades, Wesley Newcomb Hohfeld's (1879-1918) theory of fundamental legal concepts has been revisited and applied not only out of historical interest. ${ }^{1}$ For example, Robert Alexy used Hohfeld's concepts to support his theory of constitutional rights, acknowledging that " $[\mathrm{t}]$ he modern debate about legal relations was significantly promoted and influenced by the work of W. N. Hohfeld." ${ }^{2}$ In 2002, Curtis Nyquist called for an academic rediscovery of Hohfeld by assessing the advantages of applying his concepts in the classroom. ${ }^{3}$ In 2012, Ivana Tucak also argued for the use of Hohfeld's conceptual framework in legal education in countries associated with the civil law tradition. ${ }^{4}$ Despite receiving justified criticism over the past hundred years, Hohfeld's theory remains highly influential. ${ }^{5}$ For example, Kit Barker argues that Hohfeld's influence is deeper than it appears to be, and, given the growing interest in the Hohfeldian conceptual framework, he suggests two reasons why its use is more necessary than ever: to discipline and rationalize a growing rhetoric of rights and to disentangle the increasingly complex relationship between public and private law, which coincided with the rise of the modern administrative state in the twentieth century. ${ }^{6}$ At the core of Hohfeld's contribution is a conceptual framework for the analysis of the positions occupied by agents in intersubjective legal relations. In providing such a framework, Hohfeld presented a

1. See Matthew Kramer, Rights Without Trimmings, in A Debate over Rights 7 (1998); Luís Duarte d'Almeida, Fundamental Legal Concepts: The Hohfeldian Framework, 11 PHIL. Compass 554 (2016); Andrew Halpin, Fundamental Legal Conceptions Reconsidered, 16 CAN. J.L. \& JuRIs. 41 (2003).

2. Robert Alexy, A Theory of Constitutional Rights (2002), at 132.

3. See Curtis Nyquist, Teaching Wesley Hohfeld's Theory of Legal Relations, 52 J. Legal Educ. 238 (2002).

4. See Ivana Tucak, Usability of Hohfeld's Analysis of Fundamental Legal Concepts While Teaching Continental Law, in Current Problems in Legal Theory and in Comparative Law 591 (2012).

5. See Duarte d'Almeida, supra note 1, at 555.

6. See Kit Barker, Private Law, Analytical Philosophy and the Modern Value of Wesley Newcomb Hohfeld: A Centennial Appraisal, 38 Oxford J. Legal Stud. 585, 585-586 (2018). 
taxonomy composed of eight "fundamental" concepts relying on notions of opposition and correlation.

The notion of opposition has a long and prominent intellectual pedigree in Western philosophy, with the theory of opposition dating back to Aristotle (384-322 BC), who was responsible for identifying two types of opposition: contrariety and contradiction. Centuries later, these ideas were organized into a diagram known as the Aristotelian square, the conception of which is attributed to Apuleius (ca. AD 125-180) and Boethius (ca. AD 480-524). ${ }^{7}$ The spatial arrangement of the elements in the form of a square, with the addition of a third type of opposition (subcontrary relation), created an analytical tool that is now used in various fields of knowledge. In the mid-twentieth century, the French philosopher Robert Blanché (1898-1975) proposed the systematization of the concepts of opposition in the form of a hexagon, ${ }^{8}$ giving rise to the hexagon of opposition. In recent years, the theory of opposition has found new impetus, inspired by the work of researchers in the field of logic. ${ }^{9}$ This has led to novel insights concerning the theory of opposition, including its extension (to the so-called $n$-opposition theory ${ }^{10}$ ) that can account for more complex settings with three-dimensional and $n$-dimensional geometrical structures.

In the past, the square of opposition has been used as an analytical tool for building the understanding of law, not only to represent the logical relationships among Hohfeld's fundamental concepts, but also for other purposes, as, for example, by "Hart in his presentation of Bentham's "mandates' or aspects of the will."11 More recently, a number of authors have applied the hexagon of opposition to Hohfeld's fundamental legal concepts theory. ${ }^{12}$ Most of these efforts have accounted for Hohfeld's theory in direct analogy with the standard deontic hexagon. ${ }^{13}$ In this article, we discuss the application of the hexagon in this manner and propose a fuller analysis based on opposition theory. As we will show, the relations between the various legal positions can be clarified by casting the light of opposition theory on Hohfeld's conceptual analytical framework. An important aspect

7. See Jean-Yves Béziau, The Power of the Hexagon, 6 Logica Universalis 1 (2012).

8. See id. at 17.

9. See Jean-Yves Béziau, The New Rising of the Square of Opposition, in Around and Beyond the SQUARE OF Opposition 3 (2012); Alessio Moretti, Why the Logical Hexagon?, 6 Logica UNIVERSALIS 69 (2012).

10. See Alessio Moretti, The Geometry of Logical Opposition (2009) (Ph.D. thesis, University of Neuchâtel); Régis Pellissier, "Setting" n-Opposition, 2 Logica Universalis 235 (2008).

11. Halpin, supra note 1, at 41; see, e.g., Frederic B. Fitch, A Revision of Hohfeld's Theory of Legal Concepts, 10 LogiQue et Analyse 269 (1967); Leopold W. Rosdorff, Hohfeld's Theory of Fundamental Legal Concepts: A No-Revision, 16 LogiQue et Analyse 259 (1973); R.E. Robinson, S.C. Coval \& J.C. Smith, The Logic of Rights, 33 UnIv. Toronto L.J. 267 (1983); Daniel T. O'Reilly, Using the Square of Opposition to Illustrate the Deontic and Alethic Relations Constituting Rights, 45 UnIv. TORONTO L.J. 279 (1995); Heidi M. Hurd \& Michael S. Moore, The Hohfeldian Analysis of Rights, 63 Aм. J. JuRIs. 295 (2018).

12. Those related efforts are addressed in Section III.A.

13. See Giovanni Sartor, Fundamental Legal Concepts: A Formal and Teleological Characterisation, 14 A.I. \& L. 101 (2006); Hurd \& Moore, supra note 11. 
of this analysis is that the hexagons are shown to be selected projections of a logical cube, with which we are able to extend application of opposition theory to an open (or incomplete) conception of the law (one that can, if needed, distinguish between strong liberty and weak permissions). In our analysis, we also discuss the implications of abandoning the assumption of conflict-freedom and admitting seemingly conflicting legal positions. We offer a novel analysis of Hohfeld's power positions, in particular one that can address the defeasible aspect of constituted power.

The etymology of the word "opposition" reveals two characteristics, namely, the relational aspect and the idea of position. In Latin, the term oppositio is derived from ob-positio, meaning "position (positio) of something in front of $(o b)$ something else." ${ }^{14}$ Robert Alexy emphasizes that the differentiation between norm and position is of "fundamental significance"15 to the analytical treatment of constitutional rights, and that it would only make sense to treat positions in a relational context. ${ }^{16}$

This article is organized in three main sections. The first two sections present Hohfeld's fundamental legal concepts theory and the theory of opposition. The third section offers a more complete version of Hohfeld's fundamental legal concepts, arranging them into opposition structures (hexagons and cubes). The various structures contrast the contributions from other authors on the Hohfeldian conceptual framework.

\section{HOHFELD'S FUNDAMENTAL LEGAL CONCEPTS}

\section{A. Overview}

Accuracy in the use of legal concepts was one of Wesley Newcomb Hohfeld's main motivations when writing the articles that gave rise to his conceptual framework. ${ }^{17}$ One of the major obstacles to a clear understanding of the law is the false assumption that all legal relations can be reduced to rights and duties. ${ }^{18}$ Complex legal relations require other concepts. In his articles, citing numerous cases in which US courts used the term "right" in four different senses, Hohfeld demonstrated that the failure to recognize these different meanings may induce deductive errors in case analyses. ${ }^{19}$

In noting the terminological confusion derived from semantic overload of the terms "rights" and "duties,"

14. Moretti, supra note 10 , at 21.

15. AleXY, supra note 2, at 114.

16. See id. at 114 .

17. See Wesley Newcomb Hohfeld, Some Fundamental Legal Conceptions as Applied in Judicial Reasoning, 23 YAle L.J. 16 (1913); see also Wesley Newcomb Hohfeld, Fundamental Legal Conceptions as Applied in Judicial Reasoning, 26 YALE L.J. 710 (1917).

18. See Hohfeld, Some Fundamental Legal Conceptions, supra note 17, at 28.

19. See Daniel P. O'Gorman, Contract Law and Fundamental Legal Conceptions: An Application of Hohfeldian Terminology to Contract Doctrine, 33 Miss. Coll. L. Rev. 317 (2014).

20. It is important to note that the problem faced by Hohfeld is not limited to the issue of terminological inadequacy or ambiguity, but even if it were, it would still be worthy of 
composed of eight "fundamental" concepts that occur in intersubjective legal relations. Although Hohfeld does not provide categorical definitions for these concepts, the form used in his presentation, that is, the use of relations of opposition and correlation and of examples of each case, provides an understanding and dissemination of the taxonomy proposed, both within and beyond the academic environment.

Figure $1^{21}$ presents the eight legal concepts proposed in the original version in four pairs of "jural opposites" and four pairs of "jural correlatives."

Hohfeld discussed that jural opposites do not occur simultaneously for the same subject in a relationship. For example, a subject in the same legal relationship cannot simultaneously have a duty to make a payment and a privilege to not make that same payment. In turn, jural correlatives bind the two subjects involved in a legal relationship. For example, the right of a subject relating to a particular object corresponds to the duty of another subject in that legal relationship. It is important to emphasize that each fundamental legal relation binds exactly two persons, but multiple similar legal relations might be related to one subject position. ${ }^{22}$

The first two pairs of jural correlatives, right/duty and privilege/no-right, relate to a certain preestablished state of things, corresponding to positions $^{23}$ of the norms of conduct; the two subsequent pairs, power/liability and immunity/disability, relate either to a current state of affairs or to a future state, corresponding to positions ${ }^{24}$ of the norms of competence. ${ }^{25}$ It is through the exercise of a power, e.g., by making a will, that an agent establishes or changes intersubjective legal relations and therefore assigns conduct and competence norms to legal subjects.

Hohfeld describes these eight concepts as "the lowest common denominators of the law" ${ }^{26}$ and explains this analogy using a mathematical concept: "Ten fractions $(1 / 3,2 / 5$, etc.) may, superficially, seem so different from one another as to defy comparison. If, however, they are expressed in terms of their lowest common denominators $(5 / 15,6 / 15$, etc.), comparison becomes easy, and fundamental similarity may be discovered." ${ }^{27}$

\footnotetext{
"definitive recognition and persistent effort toward improvement; for in any closely reasoned problem, whether legal or non-legal, chameleon-hued words are a peril both to clear thought and to lucid expression." Hohfeld, Some Fundamental Legal Conceptions, supra note 17, at 29.

21. Id. at 30 .

22. Hohfeld coined the terms "multital" and "paucital" in place of the traditional rights concepts "in rem" and "in personam," respectively. According to Barker, "paucital rights operate against one, or a small, definite number of other persons, whereas multital rights operate against a large and indefinite class." Barker, supra note 6, at 592.

23. These positions are also known as "primary" or "first-order" positions. María Beatriz Arriagada Cáceres, Fundamentality, Interdefinability, and Circularity: Three Ideas on Hofheld Examined, 35 J. For Const. Theory \& Phil. L. 1, 7-8 (2018).

24. These positions are also known as "secondary" or "second-order" positions. Id. at 7-8.

25. See Nyquist, supra note 3, at 240-241.

26. Hohfeld, Some Fundamental Legal Conceptions, supra note 17, at 58.

27. Id. at 58 .
} 


$\begin{array}{lllll}\text { Jural Opposites } & \left\{\begin{array}{lll}\text { right } \\ \text { no-right }\end{array}\right. & \begin{array}{l}\text { privilege } \\ \text { duty }\end{array} & \begin{array}{l}\text { power } \\ \text { disability }\end{array} & \begin{array}{l}\text { immunity } \\ \text { liability }\end{array} \\ \text { Jural Correlatives } & \left\{\begin{array}{llll}\text { right } & \text { privilege } & \text { power } & \text { immunity } \\ \text { duty } & \text { no-right } & \text { liability } & \text { disability }\end{array}\right.\end{array}$

Figure 1 Fundamental Legal Concepts: Original Version

In a recent paper, Cáceres explains that Hohfeld's legal positions can be classified as active or passive according to criteria that are values-neutral and strictly formal. ${ }^{28}$ The active positions are duty, privilege, power, and disability, and the passive positions are right, no-right, liability, and immunity.

The Hohfeldian analytical method does not use any particular set of values, nor is it restricted to a given particular use, and it is "more readily transmissible from one time to another and one jurisdiction to the next." ${ }^{29}$ Hohfeld, with his methodology and taxonomy of rights, teaches us "not what to think about legal rights, but 'how' to think about them."

B. The Vagueness of the Term "Privilege" and the Solution

Concerning the concepts of duty and privilege, Hohfeld notes that when stating "privilege is the mere negation of duty, what is meant, of course, is a duty having a content or tenor precisely opposite to that of the privilege in question." ${ }^{31}$ However, the contradictory position of the duty to pay a dollar is the privilege not to pay a dollar. To work around this problem of implicit negation mentioned by Hohfeld, Fitch suggests terms to replace "privilege": "no-duty," "exemption," or "privilege not." 32 For logical consistency, from this point onward, we will replace the term "privilege" with "no-duty."

Also in relation to the term "privilege," Tucak notes that most contemporary authors replace it with the term "liberty." ${ }^{33}$ White also criticizes the use of the term "privilege" to name the position contradictory to "duty" in an article stating that "privilege, both in its legal and its everyday use, indicates what someone has in virtue of being singled out for advantageous treatment." ${ }^{34}$ Glanville Williams reports that he abandoned the term "privilege"

28. "A legal position is active if it is defined by referencing its position-holder's conduct or acts. In contrasting form, a legal position is passive when it is not defined by referencing its position-holder's conduct or acts, but rather by referencing the correlative legal positionholder's conduct or acts. . . Saying that $\mathrm{X}$ has against $\mathrm{Y}$ a right that $\mathrm{Y}$ do $\mathrm{Z}$ is equivalent to saying that $\mathrm{Y}$ has a duty to $\mathrm{X}$ to do $\mathrm{Z}$ because the position of right is passive and the position of duty is active." Cáceres, supra note 23, at 13.

29. Barker, supra note 6, at 586.

30. Id. at 586 .

31. Hohfeld, Some Fundamental Legal Conceptions, supra note 17, at 32.

32. See Fitch, supra note 11 , at 270.

33. Tucak, supra note 4 , at 7.

34. Alan R. White, Privilege, 41 Mod. L. Rev. 299 (1978). 
reluctantly and began to use "liberty." After many years of teaching at the University of London, he was convinced that the term "privilege" generated difficulties in conceptual understanding, as it refers, in its popular use, to something possessed by one person or a few people. The common objection was: "That is not a privilege, because everybody has it." ${ }^{35}$ However, we have not adopted the replacement of the term "privilege" by "liberty," for reasons that will be explained in the third section of this article.

C. The Incompleteness of Hohfeld's Scheme and the Solution

In using Hohfeld's concepts with the help of the deontic operators "obligation," "prohibition," and "permission" in the construction of the theory of constitutional rights, Robert Alexy identified a "basic incompleteness" ${ }^{36}$ arising from the fact that the original position of privilege, which he prefers to call "permission," ${ }^{37}$ considers only the abstention from an action. However, "it is not only an omission that may be permitted, but also an act," 38 and he adds, "A corresponding incompleteness can also be identified in each of the other three relations in Hohfeld's scheme." ${ }^{39}$ His solution, based on Fitch, ${ }^{40}$ eliminates incompleteness in this respect and does not render the scheme redundant: "In fact, it leads to a dual scheme, demonstrating the fruitfulness of Hohfeld's conceptions," ${ }^{41}$ as shown in Figure 2. ${ }^{42}$

The lower part of the scheme shows the converse positions, which Hohfeld calls "jural correlatives," to the respective positions in the upper part. For example, it follows that the "Right of $x$ against $y$ to an act" corresponds to the "Duty of $y$ towards $x$ to act." These two propositions have the same semantic value because they describe the same fact, either from the point of view of $x$ or from the point of view of $y$.

Some examples provided by Hohfeld concerning a particular position consider both cases of action or omission. However, his original graphic scheme does not reflect this characteristic addressed by Fitch and Alexy.

Figure $3^{43}$ shows the positions of Fitch's scheme, which formed the basis for Alexy's development and highlights the original positions corresponding to the norms of conduct of Hohfeld's original scheme. Note also that of the four newly added positions, three refer to abstentions and one to

35. Glanville Williams, The Concept of Legal Liberty, 56 CoLum. L. Rev. 1129, 1131 (1956).

36. AlEXY, supra note 2, at 136.

37. In demonstrating, by the use of deontic logic, that "the denial of a duty to do something is equivalent to permission not to do it," Alexy concludes that Hohfeld's concept of privilege is, therefore, "nothing more than a permission" and justifies the preference for the term "permission" over the other term, the use of which "might cause confusion." Id. at 134. We have not adopted this replacement for the reason explained in the previous subsection.

38. See id. at 136.

39. See id. at 136.

40. See Fitch, supra note 11.

41. See AleXY, supra note 2, at 136.

42. Id. at 136.

43. Fitch, supra note 11 , at 271-272. 


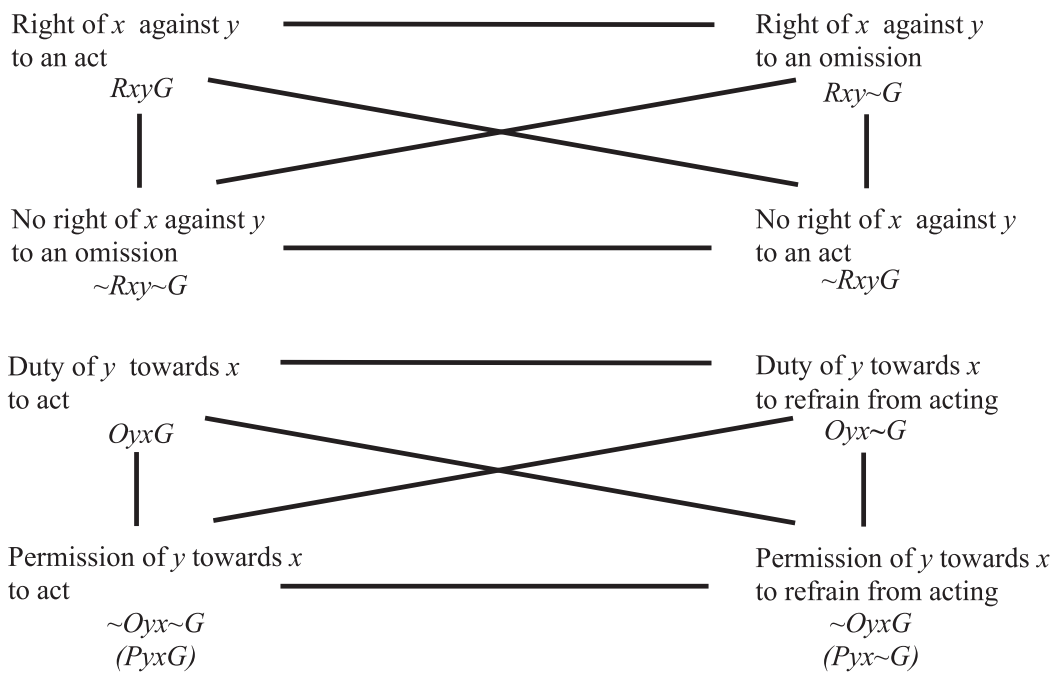

Figure 2 Hohfeld's Dual Norms of Conduct Scheme by Alexy

the permission to act (action), identified by Alexy as a "basic incompleteness" ${ }^{\prime 4}$ of the original model. Fitch explains the profusion of terms with suffixes or prefixes of negation based on the lack of ordinary words that fit the desired purpose. ${ }^{45}$

By introducing "internal negation," i.e., abstentions or omissions in addition to actions, a possible tension between duties and prohibitions is introduced into the scheme. As we will discuss later, there are two possible conceptions of a normative system depending on whether the same subject can be both bearer of an obligation and a prohibition concerning the same action. This choice is directly related to the account of contrariety in oppositional structures.

\section{From Fundamental Legal Concepts to Institutions of Law}

One of the main advantages of the Hohfeldian platform is the ability to analyze complex legal concepts, such as contracts and property, in fundamental terms. ${ }^{46}$ For example, in a given legal system, ${ }^{47}$ the concept of property can be factored into fundamental legal positions, such as the right of noninvasion by others, the power to divest the property, and the immunity of not being evicted without due process, all of which are accompanied by their

44. AleXY, supra note 2, at 136.

45. Fitch, supra note 11, at 272.

46. See Pierre Schlag, How to Do Things with Hohfeld, 78 Law \& Contemp. Probs. 185, 217 (2015).

47. Note that when we leave the level of fundamental legal concepts and enter the level of complex legal concepts, we leave an ideologically neutral territory and enter a space in which institutions of law reflect the configuration of a state of affairs at a particular time and place. 

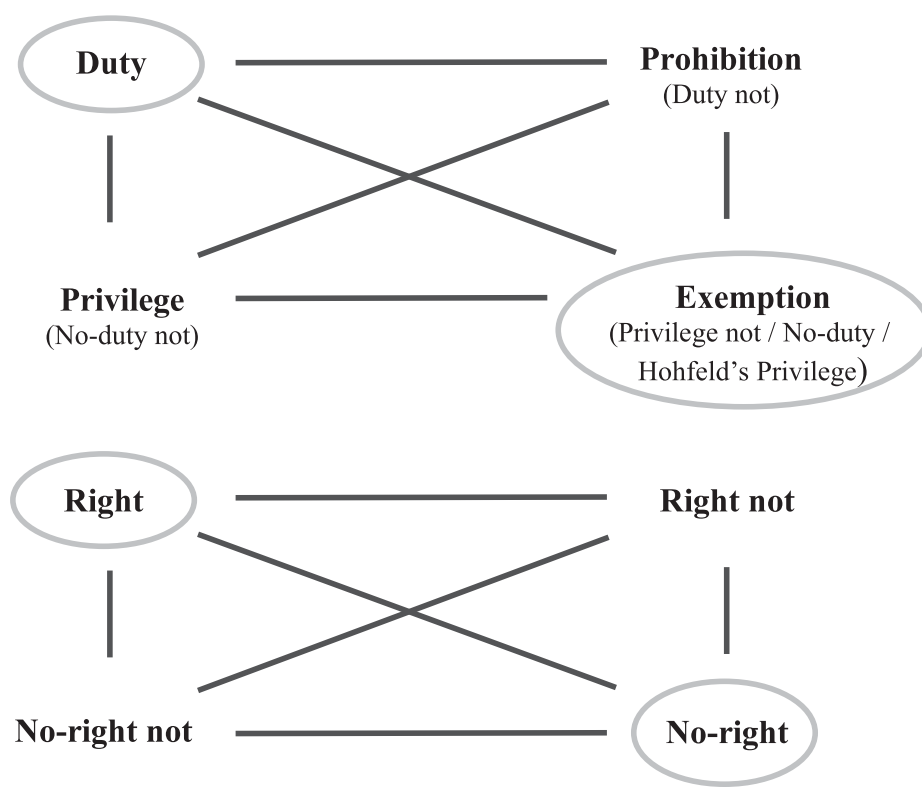

Figure 3 Fitch's Scheme Highlighting Hohfeld's Original Positions

correlative legal position. According to Barker, this "brilliant de-masking of the concept of property is said to have germinated the 'bundle of rights' theory of property (although Hohfeld himself never used that term)."48

\section{THEORY OF OPPOSITION}

A better understanding of the hexagon of opposition, which is the main purpose of this section, requires a historical and incremental approach. We begin with the square of opposition, attributed to Apuleius and Boethius. We then move on to the triangle of contrariety, identified in the nineteenth century; to the hexagon of opposition, conceived by Robert Blanché in 1953; and then, finally, to $n$-opposition as studied by Alessio Moretti, Régis Pellissier, and others in the last two decades.

\section{A. Square of Opposition}

The square of opposition is a way to geometrically articulate three opposing relations (contradictory, contrary, and subcontrary) involving propositions or concepts. Based on an example of the square of quantifiers, the relations of opposition, shown in Figure $4,{ }^{49}$ can be classified as follows: 

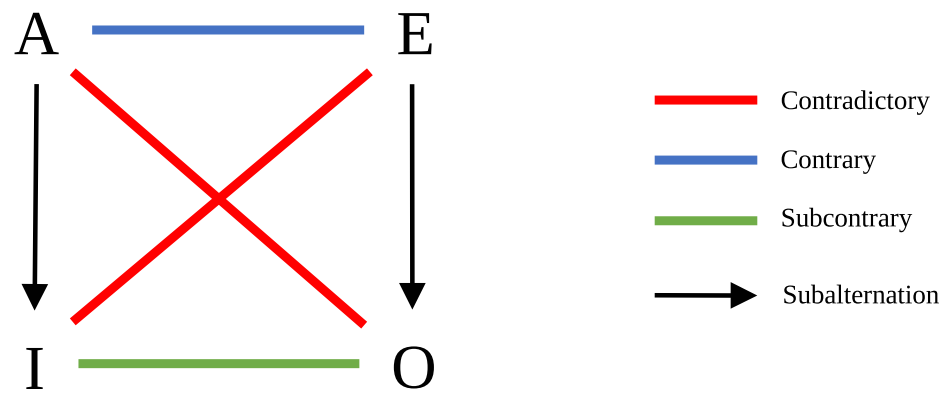

Some cats are white

Not all cats are white

FIGURE 4 Square of Quantifiers

a) A contradictory relation occurs if, and only if, the propositions do not share the same value of truth; that is, both propositions cannot be true and both cannot be false. The propositions "All cats are white" and "Not all cats are white" do not share the same truth value, i.e., they cannot both be true and they cannot both be false because they are contradictory propositions.

b) A contrary relation occurs if, and only if, the propositions can both be false, but they cannot both be true. The propositions "All cats are white" and "No cat is white" can both be false, but if we affirm both, we are led to an inconsistency, as they are contrary propositions.

c) A subcontrary relation occurs if, and only if, the propositions can both be true, but they cannot both be false. The propositions "Some cats are white" and "Not all cats are white" can both be true, but if we negate both, we have an inconsistency because these propositions are subcontrary. Conversely to the contrary relation, the inconsistency occurs in the case of both propositions being false.

The arrows, traditionally referred to as subalternate relations, are simply logical implications. ${ }^{50}$ It is easy to see that the proposition "All cats are white" implies "Some cats are white" and that the proposition "No cat is white" implies "Not all cats are white." Note also that the truth condition of the first proposition implies the truth of the second but not vice versa. As the direction is important because they are implications, arrows are used instead of lines.

Boethius chose the letters A-I-E-O, which traditionally identify the corners of the square of opposition, because they are, respectively, the first vowels of the Latin words affirmo and nego. ${ }^{51}$ 
Similarly, in addition to relations between propositions, the square of opposition can be used to represent relations between concepts. Figure 5 presents concepts of alethic and deontic logic schematized in the square of opposition. Note that the application of contrariety to "obligatory" and "prohibited" derives from the assumption that obligations cannot conflict, an assumption endorsed in "Standard Deontic Logic." ${ }^{2}$ Later, we will consider the implications of removing this requirement, and we will analyze oppositions for both the case of a conflict-free ("consistent") ${ }^{53}$ normative system and the case of a conflict-admitting ("inconsistent") normative system.

Figure 6 shows Hohfeld's concepts relating to norms of conduct using the square of opposition notation adopted here. In the upper portion, this figure shows two squares with the positions generated from right and duty, according to Fitch's dual scheme shown in Figure 3, but in the lower portion, the figure also presents a compact notation: a single square with the combination of reciprocal positions, similar to the notation used by Rosdorff and Robinson, Coval, and Smith. ${ }^{54}$ Immediately, a comparison to Hohfeld's original notation reveals that the pairs of jural correlatives (logical equivalents) and opposites (contradictory relation) are represented in a single diagram together with the contrary and subcontrary relations. Similarly, a comparison with the double diagram notations of Alexy (Figure 2) and Fitch (Figure 3) shows that the adopted notation is more succinct, without loss of expressiveness.

In the lower portion of Figure 6, the concept presented in the upper part of each vertex refers to the position of the active agent, and the bottom part refers to the position of the passive agent in the legal relation. For example, the duty of agent A toward B to perform an act (e.g., to pay an amount $x$ ) corresponds to B's right that A perform the act (whereby $\mathrm{B}$ would receive a payment of amount $\mathrm{x}$ ).

Traditionally, the square of opposition applies to attributive propositions that have the same terms. Robert Blanché adapted the original theory to allow for relations between concepts, making the theory of opposition more general and abstract. ${ }^{55}$ The central tenet of this development lies in the definition of the square of opposition starting from one concept at corner $\mathrm{A}$ and proceeding with the systematic application of negation. For example, from the "Duty" position (corner A) via the contradictory path applying the external negation, we arrive at the "No-duty" position (corner $\mathrm{O}$ ), and via the contrary path applying the internal negation, we

52. See Paul McNamara, Deontic Logic, Stanford Encyclopedia of Philosophy (Summer 2019 ed.), https://plato.stanford.edu/archives/sum2019/entries/logic-deontic/.

53. Cáceres refers to the "coherence" of positions. See Cáceres, supra note 23, at 8.

54. See Rosdorff, supra note 11, at 262; Robinson, Coval, and Smith, supra note 11, at 273.

55. See Robert Blanché, Sur l'opposition des concepts, 19 Theoria 89 (1953). 

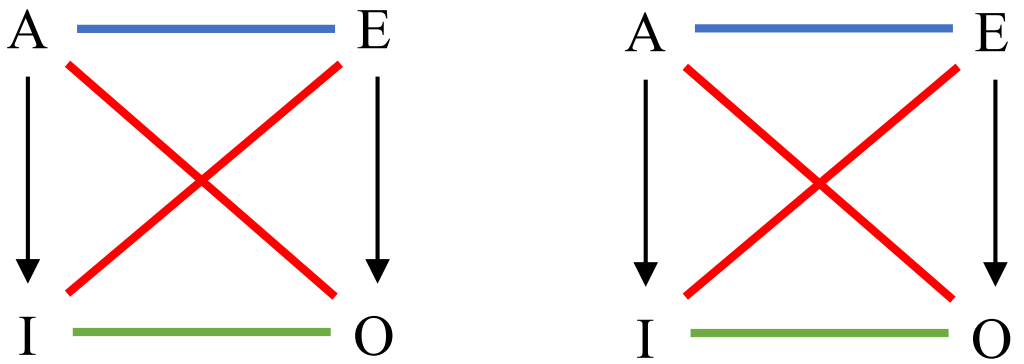

Possible Not necessary

Allowed

Not obligatory

Figure 5 Alethic and Deontic Squares of Opposition
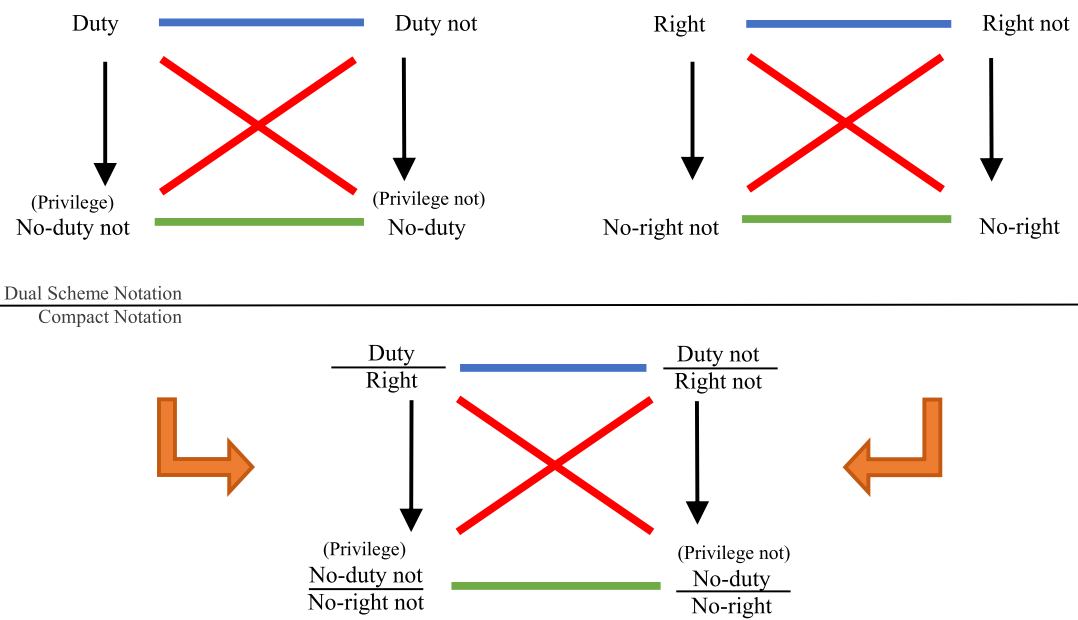

Figure 6 Hohfeld's Concepts in the Square of Opposition: Dual Scheme and Compact Notations

arrive at the "Duty not" position (corner E) ${ }^{56}$ Now, from corner E, via the other contradictory path applying external negation, we arrive at the "No-duty not" position (corner I). The same structural pattern was also applied to the rights square (on the right side of Figure 6).

Béziau describes some problems at the I and O corners of the square of opposition in relation to the use of natural language. ${ }^{57}$ From the point of view of logic, corner I of the square of quantifiers (Figure 4), where the

56. It is important to note that the "Privilege" position in Figure 6 is not Hohfeld's original "Privilege" position, whose term was replaced by "No-duty," as addressed in Section I.B.

57. See Béziau, supra note 7, at 6-7. 
quantifier "some" is located, does not exclude the possibility of "all." However, this is not the usual case in natural language. When we say, "Some cats are white," we are not usually including the case in which all cats are white.

In relation to corner O, Béziau demonstrates that the problem is not with the appropriateness of the name but with the absence of a name in natural language in most cases. ${ }^{58}$ Unlike other corners, each of which has a unique name, the name of corner $\mathrm{O}$ is usually formed by negation of the name of corner A. In the squares of quantifiers and of alethic and deontic logical concepts, the compound terms "not all," "not necessary," and "not obligatory" are used, respectively. The same phenomenon emerges in the term originally used by Hohfeld ("no-right" ${ }^{" 59}$ ).

Putting aside the lexicographic issue, Béziau believes that the problems of corners $\mathrm{O}$ and I are symmetrical, that is, intuitively, "some" is understood as "some but not all," while "not all" is understood as "not all but not none." 60 The solution to the problem of harmonizing the common sense of language with the model representing these concepts was to introduce a new corner entailing $\mathrm{O}$ and $\mathrm{I}$, thus creating the triangle of contrariety, presented in the next subsection.

\section{B. Triangle of Contrariety}

The triangle of contrariety was proposed to circumvent the problems of the square of opposition regarding natural language. Researchers from different fields of knowledge have proposed this new conformation, including the Russian logician Vasiliev (1880-1940), the Dutch linguist Otto Jespersen (1860-1943), and the French philosopher Robert Blanché. ${ }^{61}$ Figure $7^{62}$ is a diagrammatic representation of the deontic, alethic, and quantifiers schemes in the form of the triangle of contrariety.

In this proposal, unlike the square of opposition, the statements "All cats are white," "Some cats are white," and "No cat is white" are incompatible with one another and cannot be simultaneously true. Moreover, the meanings of the terms in the diagram are close to those assigned when using natural language.

Andrew Halpin proposes organizing Hohfeld's concepts, combined with deontic operators, into three triangles, known as triangles of possibilities, which, in their abstract form, have an identical structure to the triangle

58. See id. at 7-8.

59. We will retain "no-right" to keep Hohfeld's term in its original form. Later, we will discuss that "no right" (two words and no hyphen) could be used when we refer to the mere absence of "right" in an open normative system, in which a distinction between (strong) "no-right" and (weak) "no right" can be identified. Sartor uses the form "noright" (as a single word without hyphen), which can be an interesting alternative to emphasize the strong position. See Sartor, supra note 13 , at 9.

60. See id. at 9.

61. See id. at 9 .

62. Id. at 9,11 . 


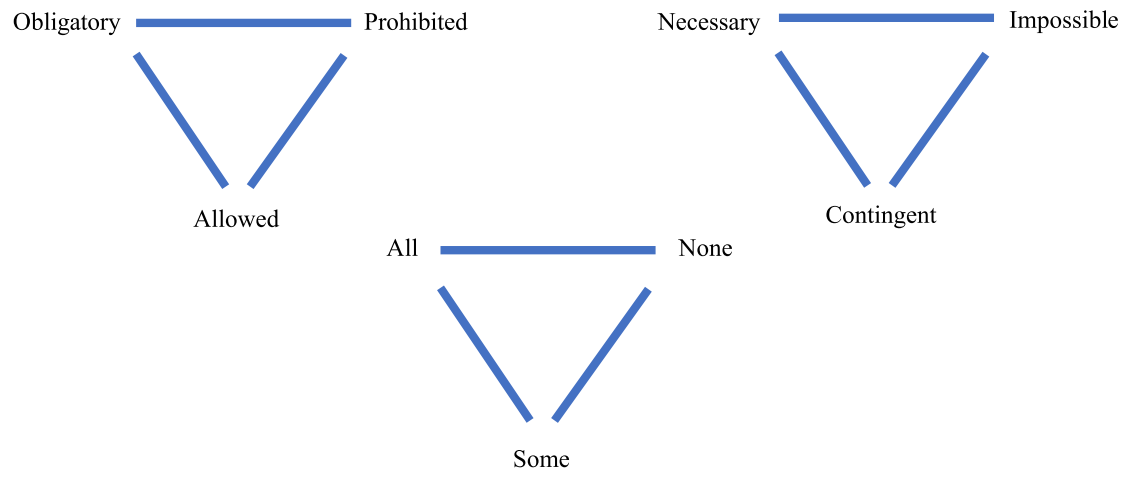

Figure 7 Deontic, Alethic, and Quantifiers Triangles of Contrariety

of contrariety, i.e., they are composed only of contrary relations. ${ }^{63}$ In a more recent work, Halpin again uses the triangle of possibilities in a comparative analysis of the conceptual schemes of Bentham and Hohfeld. ${ }^{64}$

Following this explanation of concepts related to the square of opposition and the triangle of contrariety, we move one step further in the analysis of the theory of opposition: the hexagon of opposition.

\section{Hexagon of Opposition}

The French philosopher Robert Blanché proposed to represent the concepts of opposition as a hexagon of opposition, ${ }^{65}$ which we recognize today. ${ }^{66}$

Figure $8^{67}$ shows the hexagon of quantifiers using the model proposed by Blanché, in which the new vertices are identified by the letters "U," implied by the disjunction of $\mathrm{A}$ and $\mathrm{E}$, and "Y," which implies the conjunction of I and $\mathrm{O}$. We can identify the triangle of contrariety A-E-Y and, in inverted position, the triangle of subcontrariety I-O-U. Similarly, in addition to the classic square of opposition, formed by the vertices A-E-I-O (as shown in Figure 4), we can identify two more squares of opposition: Y-A-O-U and E-Y-U-I (see Figure 9). ${ }^{68}$

According to Moretti, ${ }^{69}$ the hexagonal structure is much more interesting and expressive: instead of one symmetry, the new schematization has three

63. See Halpin, supra note 1 , at 51 .

64. See Andrew Halpin, Bentham's Limits and Hohfeld, in The Legal Philosophy and Influence of Jeremy Bentham: Essays on Limits of the Penal Branch of Jurisprudence 196 (Guillaume Tusseau ed., 2013).

65. See Béziau, supra note 7, at 17.

66. The French mathematician and logician Augustin Sesmat (1885-1957) was the first to propose the hexagonal shape; however, Sesmat's original figure did not use arrows to indicate implications. See Moretti, supra note 10, at 139.

67. Béziau, supra note 7 , at 17.

68. Moretti, supra note 10 , at 75 .

69. See id. at 139. 


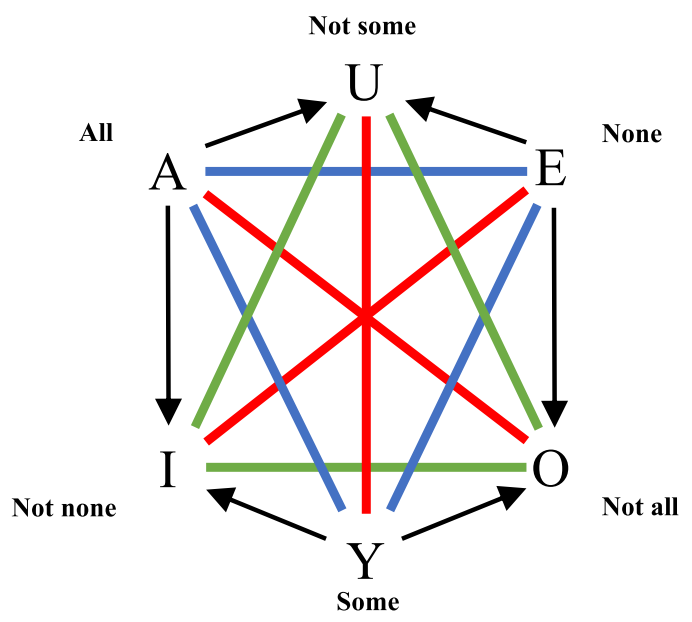

Figure 8 Hexagon of Quantifiers
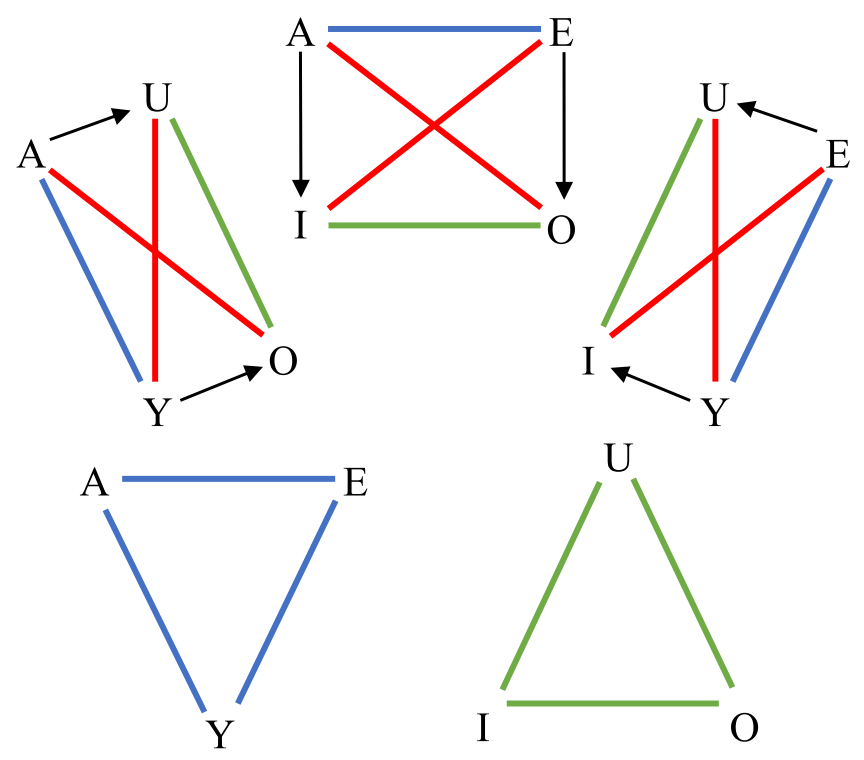

Figure 9 Three Squares and Two Triangles

axes of symmetry, as shown in Figure $10 .^{70}$ While the square of opposition has bilateral symmetry, the hexagon of opposition has rotational symmetry. In discussing "the pleasures that arise from symmetry,"71 Montesquieu

71. De Montesquieu, Essay on Taste, in An Essay on TASTE 257, 278 (1754). 

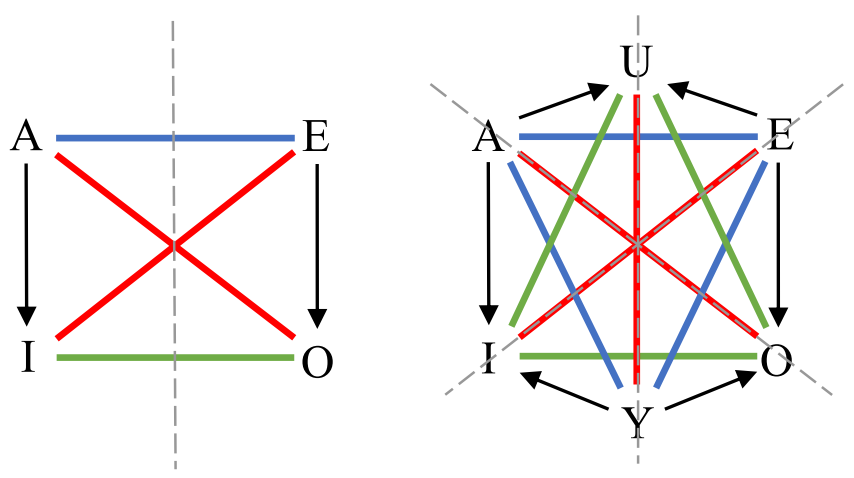

Figure 10 Comparison of Symmetries

"argues that symmetry retains the tension of order and variety in a coherent and effective fashion": ${ }^{72}$

One of the principal causes of the pleasure, which the mind receives in the contemplation of the various objects that are presented to it, is the facility with which it perceives them. Hence symmetry is rendered agreeable, as its similar arrangements relieve the mind, aid the quickness of its comprehension, and enable it, upon a view of the one half of an object, to form immediately an idea of the whole. ${ }^{73}$

This new structure can accurately represent, for example, all the relations between comparison operators in mathematics. In this example (Figure 11), ${ }^{74}$ the new diagram shows in a schematic, direct, and complete way the various opposing relations:

a) Contradictory relations: For example, something "greater than" is incompatible with something "less than or equal to," as in the case that $5>3$ (true) is contradictory to $5 \leq 3$ (false).

b) Contrary relations (incompatibilities): Something "greater than" cannot be "less than" but also cannot be "equal to," as in the case that $5>3$ (true) is contrary to the cases of $5<3$ (false) and $5=3$ (false).

c) Subcontrary relations (compatibilities): Something can simultaneously be "greater than or equal to" and "different from," "greater than and equal to" and "less than or equal to," or even "less than or equal to" and "different from." For example, $5 \geq 3$ (true) is compatible with $5 \neq 3$ (true).

72. Giora Hon \& Bernard R. Goldstein, From Summetria to Symmetry: The Making of a Revolutionary Scientific Concept (2008), at 142.

73. De Montesquieu, supra note 71, at 278.

74. Moretti, supra note 10, at 142. 


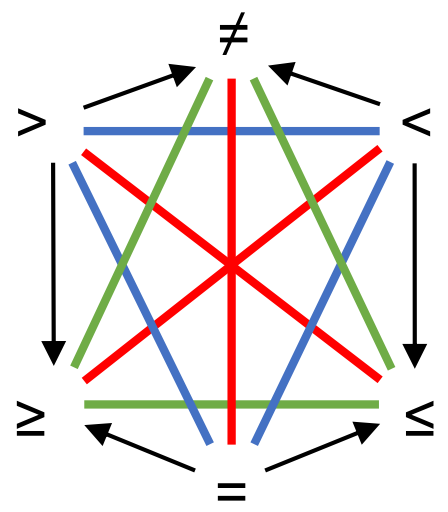

Figure 11 Comparison Operators in Mathematics

d) Implication (subalternate relation): These relations are indicated by black arrows. For example, $5>3$ (true) implies $5 \neq 3$ (true) and $5 \geq 3$ (true).

The application of the hexagon in this manner assumes that the three alternatives in the triangle of contrariety (A, E, Y) are not only mutually incompatible, but also that, together, they exhaust all of the possibilities, constituting a trichotomy. In other words, it assumes that the disjunction $A \vee E \vee Y$ is always true, and hence, the mathematical comparison relations are a total order: given any two numbers, one is either greater than (A), lower than $(\mathrm{E})$, or equal to $(\mathrm{Y})$ the other. Another example of trichotomy can be found in a simple three-state red-green-yellow traffic signal. If the traffic light is red (A), then it is neither green (E) nor yellow (Y) (i.e., red implies not yellow and implies not green). If such a traffic light is neither yellow nor green, then it is red. ${ }^{75}$

D. Opposition Theory beyond the Hexagon

Pellissier has characterized the hexagon discussed in the previous subsection as forcé (or strong) and proposed a weak version of the hexagon that admits a fourth possibility beyond $\mathrm{A}, \mathrm{E}$, and $\mathrm{Y}^{76}$ In the case of the traffic light, this fourth possibility could account for the state in which it is completely turned off, and thus neither red, green, nor yellow. In this case, we cannot infer that it is red from its not being yellow nor green, as we are admitting the possibility that it can be simply turned off. Formally, in a weak hexagon it does not follow that $\mathrm{Y}=\mathrm{I} \wedge \mathrm{O}$, but only that $\mathrm{Y} \rightarrow \mathrm{I} \wedge \mathrm{O}$.

75. Although there are some interesting comparisons between the normative positions and the lights in a semaphore, we will not explore this here, and use the traffic light simply as an intuitive commonsense example of a trichotomy.

76. See Pellissier, supra note 10, at 238. 


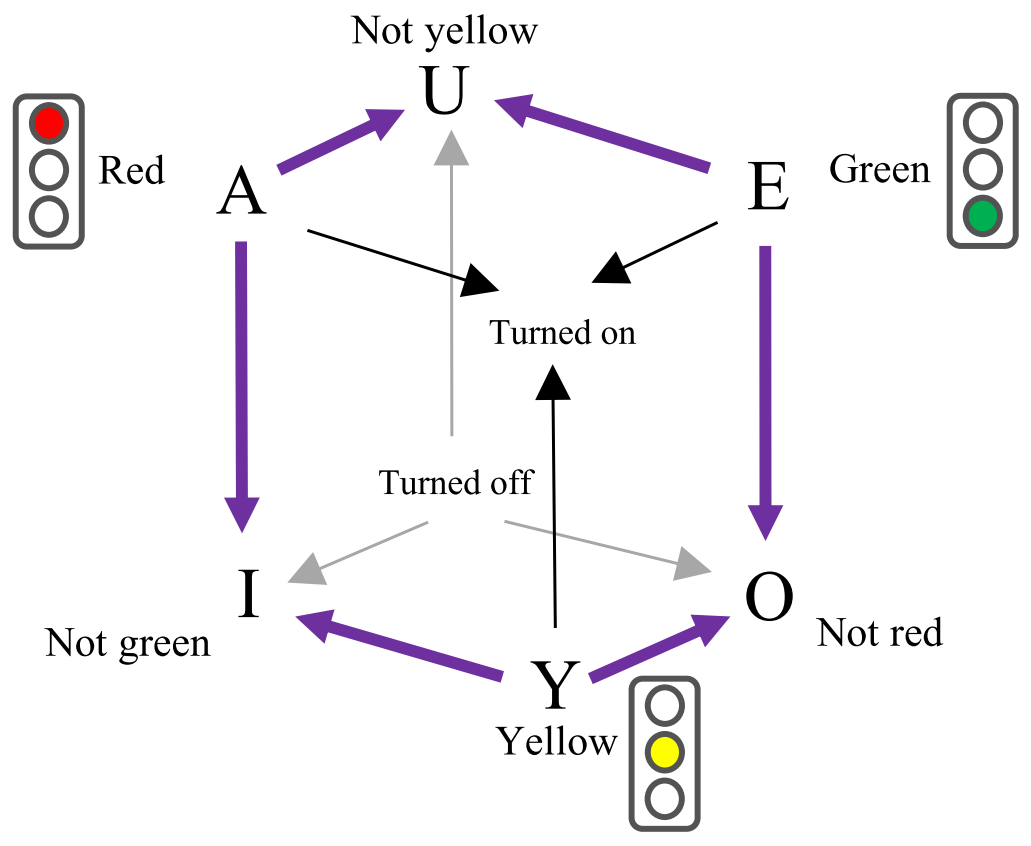

Figure 12 The Logical Cube

Pellissier and Moretti noted that instead of a triangle of contrariety, if there are four alternatives, we have a three-dimensional geometrical structure with four vertices, namely, a tetrahedron of contrariety. ${ }^{77}$ The four mutually incompatible vertices jointly exhausting all possibilities became red (A), green $(\mathrm{E})$, yellow $(\mathrm{Y})$, and turned off. The same happens with the triangle of subcontrariety. When combined, their eight vertices of the two tetrahedrons form a "logical cube" as shown in Figure 12. The contradictory oppositions apply to opposing vertices of the cube, following the hexagon, but in three dimensions. The figure reveals that the weak hexagon (emphasized) is actually a selected projection of the three-dimensional structure. We show later that such a cube is required to account for a normative system in which it is possible for a conduct to be neither obligatory, forbidden, nor (strongly) facultative.

Prior to revisiting Hohfeld's set of concepts in light of opposition theory, it is worth recognizing that some authors proposed a reduction in the number of concepts. Halpin claimed that the set of eight concepts could be reduced to two (right and duty) ${ }^{78}$ Globe claimed that all legal relations are derived from powers. ${ }^{79}$ Corbin argued that all legal relations are derived 
from duties and powers. ${ }^{80}$ We agree with Saunders that "Corbin appears to have been correct," ${ }^{81}$ but only for a closed (complete) legal system, which does not distinguish between weak and strong permission (or, alternatively, weak and strong obligation). ${ }^{82}$ In a complete system, it is possible to derive the other positions from duty positions according to the square of opposition structural pattern. We also agree with Saunders that "the greater than necessary number of terms in Hohfeld's scheme does not constitute a serious criticism," $" 83$ and his justification is very well founded, as shown with an example from logic:

Logic tells us, for example, that we can get along without the use of the word "and", since it may always be replaced by a combination of "not" and "or." That does not mean, however, that a logical system should not employ "and" as a logical connective. Its regular occurrence justifies its inclusion, and indeed the system would be cumbersome without it. Similarly, while duties and powers, or rights and powers, may be sufficient to express the other relations, greater clarity and correspondence with everyday language justify the inclusion of the additional concepts, while keeping in mind the relations between the terms. ${ }^{84}$

By the same token, one could express the order relations in mathematics using a combination of the comparison operators ">" and "=" with the logical operators " $\wedge$ " (and) and " $\sim$ " (not), excluding the symbol "<." For example, the formula " $x \sim>y \wedge x \sim=y$ " ( $x$ not "greater than" $y$ and $x$ not "equal to" $y$ ) could be used in place of " $x<y$ " ( $x$ "less than" $y$ ) because the former expresses the same propositional content as the latter. However, the latter form is more appropriate as the specialized operators provide conciseness and clarity to the mathematical expressions. In any case, for legal positions, the reduction is not always an option as it is contingent on the assumption of a complete normative system. For a fuller analysis, we will consider all the combinations of assumptions on completeness and conflict-freedom in a normative system.

\section{FUNDAMENTAL LEGAL CONCEPTS IN THE HEXAGON OF OPPOSITION}

The previous section presented an instructive example from mathematics (Figure 11) in which the relations between the concepts of order were

80. "It has seemed to me that both judicial and popular usage are in almost complete agreement on the meaning of two of these terms: Duty and Power. Working from each of these as a starting point, and proceeding by the aid of correlatives and negatives, we can arrive definitely and quickly at the concepts described by Hohfeld's other six terms." Arthur L. Corbin, Jural Relations and Their Classification, 30 YALE L.J. 226, 230 (1921).

81. Kevin W. Saunders, A Formal Analysis of Hohfeldian Relations, 23 Akron L. Rev. 465, 471 (1989).

82. See Carlos E. Alchourrón, Logic of Norms and Logic of Normative Propositions, 12 LogIQUE ET ANALYSE 242, 249-252 (1969).

83. Saunders, supra note 81 , at 471 .

84. Id. at 471. 


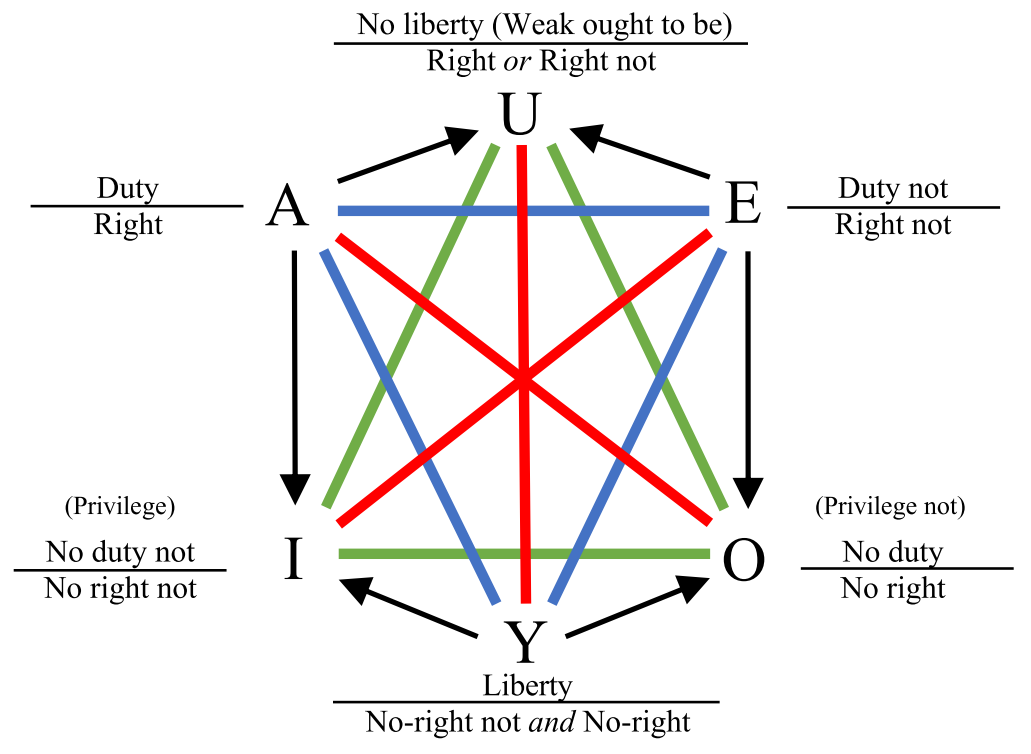

Figure 13 Hexagon for Norms of Conduct

fully represented in a single diagram. This section is intended to draw together Hohfeld's concepts with similar completeness. To that end, we must identify the concepts that complement Hohfeld's eight original concepts in order to form hexagons.

\section{A. Hexagon for Norms of Conduct}

In regard to norms of conduct, the concepts of liberty and no liberty (weak ought to be) seem to be the most appropriate to fill the aforementioned gap. Figure 13 shows the proposed conformation, adopting a weak hexagon.

Several authors, ${ }^{85}$ directly or indirectly influenced by Williams,${ }^{86}$ began to use the term "liberty" to name the position originally known as "privilege." In fact, Hohfeld himself used "liberty" as a synonym of "privilege," stating, "Liberty, considered as a legal relation ... must mean, if it have any definitive content at all, precisely the same thing as privilege. ${ }^{87}$ However, using Alexy's concepts, ${ }^{88}$ this applies only to positive liberty, where the object of liberty is a single action. The existence of a privilege (or positive liberty) correlates, in the position of the opposite end, to a no-right. In turn,

85. See, e.g., Leonard Wayne Sumner, The Moral Foundation of Rights (1987); Robinson, Coval, and Smith, supra note 11; Tucak, supra note 4; Duarte d'Almeida, supra note 1.

86. See Williams, supra note 35.

87. Hohfeld, Some Fundamental Legal Conceptions, supra note 17, at 36.

88. See AleXY, supra note 2, at 140. 
negative liberty, ${ }^{89}$ characterized by Alexy as legal liberty, necessarily has as its object an action alternative, ${ }^{90}$ as in the case of liberty of expression of opinion, which can be expressed as "Agent $x$ is legally permitted to express his opinion, and he is legally permitted not to express his opinion."91

From a relational point of view, the position of liberty of $x$ correlates to two positions for $y$ (Figure 13):

a) A no-right of person $y$ that person $x$ does not perform the object action of liberty (a "no-right not"); and

b) A no-right of person $y$ that person $x$ performs the object action of liberty.

This characterization of the concept of liberty as being broader than a simple privilege can be seen in the works of several other authors:

a) Singer, by analyzing the contribution of John Stuart Mill (18061873), contends that under the utilitarian theory, liberties should be accompanied by duties on others not to interfere. ${ }^{92}$

b) Fiorito and Vatiero maintain the distinction between liberties and privileges, as liberties include privileges to perform a given act and claims to noninterference with performing it. ${ }^{93}$

c) O'Reilly asserts that the concept of full liberty is composed of two half-liberties: the liberty to do and the liberty not to do. ${ }^{94}$

d) Rosdorff holds that privilege and privilege not portray two different choices between doing and not doing. ${ }^{95}$

One of the first critics of Hohfeld, Albert Kocourek, argued for the conformation proposed here for the concept of liberty, as reported by Goble: "If Professor Kocourek is correctly understood, his term 'liberty' is analyzable into two privileges - a privilege to do the act, and a privilege to not do the act." ${ }^{96} \mathrm{He}$ adds, "In his discussion of this point, [he] insists on substituting for each of these privileges the term 'liberty' and then showing that each is not a liberty because there is no freedom or choice of action." 97

89. Id. at 141.

90. Qualification of the object of liberty can be derived from "explicit permissive norms," common in constitutional matters, which play an important role signaling the "'ought-limits' to lower levels." Id. at 147.

91. Id. at 143 .

92. Joseph William Singer, The Legal Rights Debate in Analytical Jurisprudence from Bentham to Hohfeld, 1982 Wis. L. Rev. 975, 999 (1982).

93. Luca Fiorito \& Massimiliano Vatiero, Beyond Legal Relations: Wesley Newcomb Hohfeld's Influence on American Institutionalism, 45 J. Econ. Issues 199 (2011).

94. O’Reilly, supra note 11, at 290. See also Joel Feinberg, Rights, Justice, And the Bounds of Liberty: Essays in Social Philosophy 175 (2014) (arguing about the distinction between halfliberty and liberty).

95. Rosdorff, supra note 11, at 262.

96. George W. Goble, Negative Legal Relations Re-examined, 5 ILL. L. Q. 36, 49 (1922).

97. Id. at 49 . 
Alexy also subscribes to this notion in his formal definitions of "liberty" (LG) and "non-liberty" ( LG) with the help of the deontic operators of permission $(\mathrm{P})$ and obligatoriness $(\mathrm{O})$, as follows: ${ }^{98}$

a) $\mathrm{LG}={ }_{\mathrm{def}} \mathrm{PG} \wedge \mathrm{P} \sim \mathrm{G}$. Liberty is equated to the conjunction of two positions in the agent that possesses it (logical operator AND: $\wedge$ ).

b) $\sim \mathrm{LG}={ }_{\text {def }} \mathrm{O} \sim \mathrm{G} \vee \mathrm{OG}$. Non-liberty is equated to the disjunction of two positions (logical operator OR: $\vee$ ).

Alexy explains his concept of "non-liberty" as follows: "A legal subject $x$ is legally unfree as regards a certain act $(\sim \mathrm{LG})$, if the omitting of the act $(\mathrm{O} \sim \mathrm{G})$, or the performance of it $(\mathrm{OG})$, is legally commanded." ${ }^{.99}$ For example, the existence of a creditor, occupant of the "right" position, implies to the debtor a position of "non-liberty," that is, the debtor is required to perform a certain act (to make the payment).

At this point we can clarify that the hexagon can be applied in the two different manners we identified earlier. If it is considered a strong hexagon, we have that $\mathrm{Y}$ is exactly the conjunction of $\mathrm{I}$ and $\mathrm{O}$, and hence liberty is reducible to a mere conjunction of privileges $(\mathrm{LG}=\sim \mathrm{O} \sim \mathrm{G} \wedge$ $\sim \mathrm{OG})$. This is what Sichelman concluded in a recent analysis of the privilege-liberty concern. ${ }^{100}$ Sichelman concludes that a "common" liberty is an aggregate of two fundamental Hohfeldian relations (a positive privilege and a negative privilege), and hence is a "complex jural relation."

We propose that the hexagon be interpreted in the weak sense proposed by Pellissier ${ }^{101}$ to account for a (fourth) possibility: a normative gap in which an act is neither commanded nor prohibited nor facultative. See Figure 14 for the corresponding logical cube, with the embedded weak hexagon (emphasized in the figure). In this setting, "liberty" adopts the same standing as the "duty" and the "duty not" positions. The "liberty" position implies "no duty not" and "no duty," 102 in the same way that the "duty" position implies "no duty not" and "no liberty" positions and that the "duty not" position implies "no duty" and "no liberty." By showing how "liberty" fits the Y vertex of the weak hexagon in the cube, we clarify that "liberty" is not reducible to "no duty" and "no duty not"; instead, it is a nonderived relational legal position (RLP). If defined as a "complex" jural position, it must be understood as a conjunction of strong permissions (corresponding to strong faculty), and not a conjunction of the mere absence of duties.

98. See AleXy, supra note 2, at 145.

99. Id. at 145 .

100. See Ted Sichelman, Very Tight 'Bundles of Sticks': Hohfeld's Complex Jural Relations (San

Diego Legal Studies Paper No. 17-286, 2017), http://ssrn.com/abstract=2947912.

101. Pellissier, supra note 10, at 239.

102. Note that we do not use hyphens for any of the weak forms. 


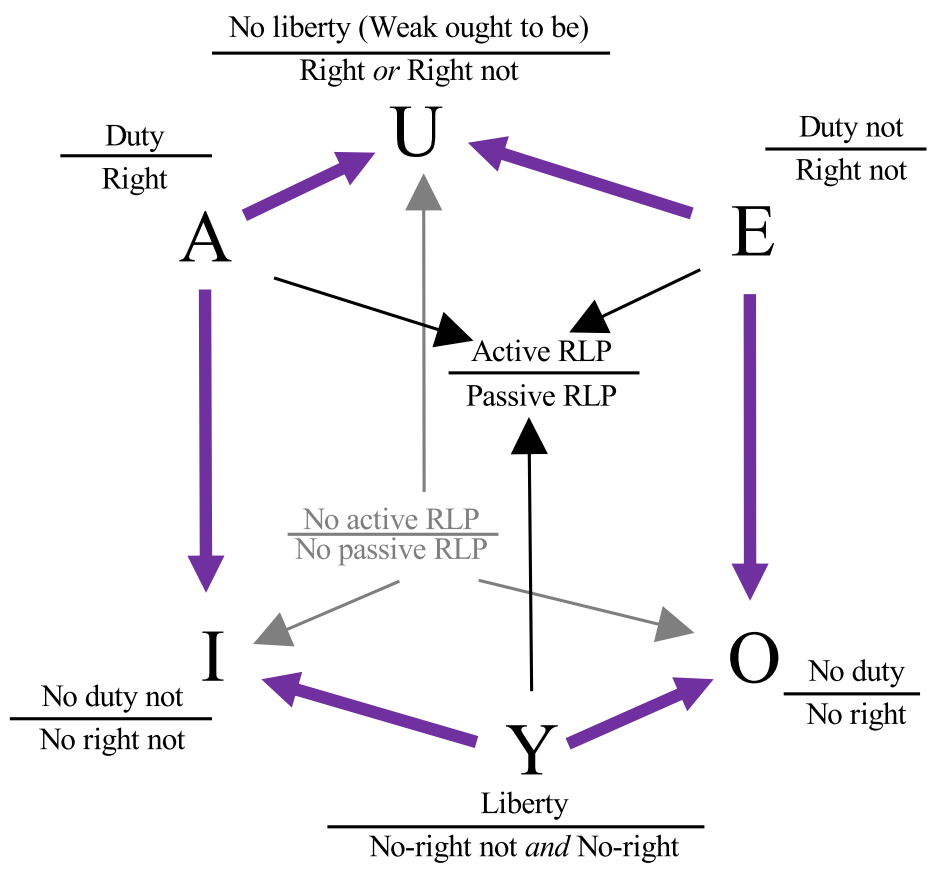

Figure 14 Weak Hexagon Projection on Logical Cube

Alchourrón explicitly anticipated the need to go beyond a trichotomy in his study of what he calls "normative logic." ${ }^{103}$ He discussed that obligation, prohibition, and (strong) faculty in normative logic only form a trichotomy if and only if the proposition and its negation are normatively determined. This explains why strong permission to act without strong permission to omit as well as strong permission to omit without strong permission to act do not figure in our triangle of possibilities. Our triangle of possibilities embedded into the cube concerns what Sartor calls "complete" qualifications, ${ }^{104}$ i.e., those that determine "the deontic status of both the action they are concerned with and the complement of that action."

The cube reveals two other vertices not placed in the weak hexagon, but also important to our analysis. In the vertex placed in front, we have the disjunction of all the (completely qualifying) legal positions in contrariety (representing thus the existence of a legal relation, with active and passive legal positions determining the deontic status of the act and its omission). In the vertex placed in the back (in contradictory position to the one in the front), we have the mere negation of the three relations, i.e., no legal relation between two subjects. As pointed out by Moretti, in the cube the four 
contraries are equidistant and the same can be said of the four subcontraries. ${ }^{105}$ Contradictory relations are represented with maximal distance across the cube.

The hexagon has been applied by other authors previously in the analysis of Hohfeld's theory, mostly from the perspective of the deontic hexagon. For example, Hurd and Moore ${ }^{106}$ present the "Standard Deontic Hexagon" focusing on deontic concepts and use that as a backdrop to analyze the Hohfeldian jural relations. The hexagon they present has only one occurrence of the subcontrary relation between the $\mathrm{PE}(\mathrm{A})$ and $\mathrm{PE}(\sim \mathrm{A})$ vertices and not three subcontrary relationships that form the triangle of subcontrariety. Their notation for the subcontrary relation is proposed as two arrows separated by a vertical bar. They adopt McNamara's deontic hexagon instead of Kalinowski's. ${ }^{107}$ As discussed in depth by Moretti, ${ }^{108}$ McNamara's structure (and hence, Hurd and Moore's) is equivalent to a pentagon, because it does not have the triangle of subcontrariety. Because of the biconditional relating $\mathrm{OP}(\mathrm{A})$ and $\mathrm{OP}(\sim \mathrm{A})$, there is redundancy in Hurd and Moore's hexagon, and a missing vertex when compared to Kalinowski's. ${ }^{109}$ Regardless of these criticisms, they offer a careful analysis of Hohfeld's theory assuming "the full package of a standard deontic logic of permission"110 (conflict-freedom and completeness). Because of this, differently from us, they do not recognize a notion akin to "strong liberty" and in their framework maintain privilege as absence of duty not (i.e., the mere optionality of standard deontic logics). This position is explicit in their account, and they claim, following Hart and Mullock, that Hohfeld's opposition is simply negation external to the deontic operators (contradiction). Our analysis shows that this interpretation of Hohfeld needs to be more nuanced if one assumes an open normative system; contradiction still leads us from one vertex of the cube to the farthest other vertex, but then the three positions in the triangle of contrariety- "duty" (A), "duty not" (E), and "liberty" $(\mathrm{Y})$ - are opposed to weak positions, which are the result of applying negation to the existence of a normative position-"no duty," "no duty not," and "no liberty." "If we take Hohfeld's opposition to mean negation in this sense, then "liberty" cannot be reached from "duty" or "duty not," and hence, it stands on its own as a legal position. The correlatives in the denominator of the triangle of contrariety are "right," "right not," and "no-right and no-right not." The opposed weak

105. See Moretti, supra note 10, at 184.

106. Hurd \& Moore, supra note 11, at 19.

107. See McNamara, supra note 52; Georges Kalinowski, La logiQue déductive: essai de PRÉSENTATION AUX JURISTES (1996).

108. See Moretti, supra note 10, at 314-315.

109. See id. at 315 .

110. Hurd \& Moore, supra note 11, at 21.

111. "No liberty" could also be termed (weak) "ought to be," as it corresponds to a disjunction of "weak obligations." 
positions in the triangle of subcontrariety are "no right" $(\mathrm{O})$, "no right not" (I), and "right or right not" $(\mathrm{U}) .{ }^{112}$

Sartor approaches the incompleteness of normative system by stating that the nonderivability of a legal proposition cannot be equated to its negation. ${ }^{113}$ When considering permissions, he distinguishes the nonderivability of an obligation to omit (a weak permission) from the derivability of the negation of an obligation to omit (a strong permission in his view). A "privilege" for him is exactly the strong permission to omit. ${ }^{114,115}$ To take into account Sartor's view, it is key to recognize that external negation applies to derivability. In this case, the oppositions in the weak hexagon embedded in the logical cube correspond to the contradiction between deriving and not deriving a legal position; "duty," "duty not," and "liberty" (for him, "faculty") constitute mutually exclusive derivations in the triangle of contrariety, and "no duty," "no duty not," and "no liberty" in the triangle of subcontrariety should be understood as the nonderivability of the positions in opposing vertices. Therefore, in his examination of the Hohfeldian notions, what he refers to as "incompatibility" is not the external negation on derivability; ${ }^{116}$ from the perspective of derivability, it is internal negation of the positions being derived. Note that it is still external to the deontic operator.

Sileno, Boer, and van Engers ${ }^{117}$ take the hexagon of oppositions applied to the "deontic terminology used . . by Leibniz and Bentham" and isolate a triangle of contrariety from that, "using the formal notation proposed by Sartor." 118 Their triangle together with the correlative relations forms what they call "the Hohfeldian prisms." ${ }^{119}$ They do not discuss the consequences of an incomplete normative system, using a strong hexagon. Their interpretation of the potestative square is radically different from what we present here. They address that square via obligations, prohibitions, and liberty to recognize constitutive norms. Hence, they refrain from addressing the constitutive aspect, which is essential to the potestative square, as discussed in Section III.B.

Having discussed the implications of (in)completeness, we now turn to the consequences of admitting seemingly "conflicting" legal positions. We understand that legal positions are in conflict whenever they cannot be

112. Strictly, the denominator of the U vertex should be named "no no-right or no no-right not," but this is clearly most unusual. It should be clear, nevertheless, that we mean a weak form of right here as the correlative of the weak duties that constitute a "no liberty."

113. See Giovanni Sartor, Legal Reasoning: A Cognitive Approach to the Law, 5 A TrEatise of LegaL Philosophy and General Jurisprudence 497 (2005).

114. Sartor does not follow Fitch's proposal concerning terminology and maintains "privilege" (and not "privilege not") as the opposite of "duty."

115. See Sartor, supra note 13, at 9 (Definition 7.2).

116. See id. at 9 .

117. Giovanni Sileno, Alexander Boer \& Tom van Engers, On the Interactional Meaning of Fundamental Legal Concepts, in Frontiers in Artificial Intelligence and Applications 39, 45 fig.4 (2014).

118. See Sartor, supra note 13, at 14.

119. See Sileno, Boer \& van Engers, supra note 117, at 46 fig.5 (left-hand side). 
fulfilled at the same time by their bearers. Ruiter calls these situations "irreconcilable." ${ }^{120}$ In standard deontic logic, such irreconcilability between obligation and impermissibility becomes plain in the so-called possible world semantics. In that semantics, a proposition " $p$ is obligatory iff it holds in all the acceptable worlds, . . impermissible iff it holds in no such world. . . and optional iff $p$ holds in some such world, and so does $\sim p, " 121$ corresponding to the three possibilities in the trichotomy formed by the quantification "all," "no," and "some" (i.e., "not all" and "not none"). Following standard deontic logic (but not primarily motivated by that), Hurd and Moore explicitly shun conflicting obligations, thus leading to the contrariety in their strong hexagon.

However, there is certainly no consensus over this matter. Kramer discusses that while "conflicting duties. . . involve competing demands on the duty bearer," 122 they are "far from inconceivable." 123 Thus, in a complete, conflict-tolerating system, there is no contrariety to be established between "duty" and "duty not," as it is admissible for a subject to be under conflicting duties. If a complete system is also assumed, then the sole type of opposition is the contradiction, either between "duty" and "no duty"124 (or "privilege not"), or between "duty not" and "no duty not" (or "privilege"). In other words, these are simple dichotomies, and cannot form a hexagon.

However, if the conflict-tolerating system is considered incomplete, a trichotomy can still be established between "duty or duty not" (ought to be) (A), (strong) "liberty" (E), and the absence of a (fully qualifying) legal position ("no command") (Y). In this case, a strong hexagon can be defined, with mere negation of liberty in (I) ("no liberty") and the conjunction of mere negation of duty and mere negation of duty not in $(\mathrm{O})$ ("no duty and no duty not"). The absence of a legal position $(\mathrm{Y})$ is the mere conjunction of I and $\mathrm{O}$ ("no duty, no duty not and no liberty"). Finally, in this hexagon, $\mathrm{U}$ is the disjunction of "duty or duty not" (A) and "liberty" (E) (i.e., reflecting the existence of some legal position, "some command"). Note that this is the cube with the vertices "duty" and "duty not" collapsed by disjunction.

Table 1 summarizes our analysis of relations for conduct norms based on the different stances with respect to a normative system, and the opposition structures that can be employed in the account of legal positions (correlative positions have been omitted for the sake of conciseness):

120. Dick W.P. Ruiter, Legal Institutions (2001), at 24.

121. McNamara, supra note 52.

122. Kramer, supra note 1 , at 19.

123. Id. at 18 .

124. In a complete system, there is no distinction between weak and strong forms, and hence, "no duty" and "no-duty" can be used in the same sense. 
Table 1

Implications of Assumptions on a Normative System

\begin{tabular}{lll}
\hline Closed (i.e., complete) & \multicolumn{1}{c}{ Open (i.e., incomplete) } \\
\hline Conflict-tolerating & $\begin{array}{c}\text { Dichotomy, no hexagon. Only } \\
\text { contradictory opposition } \\
\text { between "duty" and "no } \\
\text { duty=privilege not" (likewise } \\
\text { between "right" and "no } \\
\text { right"). }\end{array}$ & $\begin{array}{l}\text { Trichotomy. Strong hexagon } \\
\text { with "duty or duty not," } \\
\text { "liberty," and "no command" } \\
\text { in the triangle of contrariety. }\end{array}$ \\
$\begin{array}{c}\text { Trichotomy. Strong hexagon } \\
\text { Coflecting standard deontic } \\
\text { logic. Interdefinability of } \\
\text { "duty," "duty not," and } \\
\text { "liberty" (mere faculty) in } \\
\text { the triangle of contrariety. }\end{array}$ & $\begin{array}{l}\text { Tetrachotomy between "duty," } \\
\text { "duty not," (strong) "liberty," } \\
\text { and no relational legal } \\
\text { position. Logical cube } \\
\text { (or weak hexagon } \\
\text { embedded in the logical } \\
\text { cube). Contradiction in the } \\
\text { weak hexagon oppose strong } \\
\text { and weak positions. }\end{array}$ \\
\hline
\end{tabular}

As we have discussed, most of the authors that have applied the theory of opposition to Hohfeld's concepts either have adopted a complete normative system (such as Hurd and Moore ${ }^{125}$ ) or at least have not explicitly accounted for openness (Sileno, Boer \& van Engers, ${ }^{126}$ Kramer $^{127}$ ). As for Hohfeld himself, there is ample debate about the "correct way of understanding the purely negative character of Hohfeldian relations of privilege/ no-right and disability/immunity." 28 Cáceres hypothesizes that "Hohfeld was not aware of the doubts and problems produced by the ambiguity with which he uses the terms considered purely negative"129 and explains that this is "because his work was produced long before discussions about if a difference exists, and if so, of what kind, between nonnormative situations and situations instituted by permissive norms or norms of disability or incompetence." 130 By discussing Hohfeld's notions in light of the cube, we have explicitly taken nonnormative situations into account. While that does not settle what Hohfeld meant by "purely negative," the use of external and internal negation in the cube clarifies what is at stake (and the weak positions are "purely negative" in a specific sense).

125. See Hurd \& Moore, supra note 11.

126. See Sileno, Boer \& van Engers, supra note 117.

127. See Kramer, supra note 1.

128. See Cáceres, supra note 23, at 18.

129. Id. at 19.

130. Id. at 19 . 
B. Hexagon for Constitutive Norms ${ }^{131,132}$

Different from the norms of conduct, through which Fitch (Figure 3) and Alexy (Figure 2) proposed a double scheme of legal positions with the support of deontic modalities, we did not find similar development for positions related to the constitutive norms. For this reason, before we propose the hexagon of constitutive norms, we will create the double scheme of constitutive norms and legal positions. To this end, we begin our analysis with a discussion of the central concept of legal competence.

Although some scholars have distinguished between the notions of power and competence, we often find the interchangeable use of the terms "power" and "competence" or a preference for one of them according to the legal tradition of the author's origin. The term "power" is generally preferred by Anglo-Saxon authors such as Bentham, Hohfeld, and Hart ${ }^{133}$ and was adopted by the translator of Alexy's work into English. In their turn, Scandinavian authors such as von Wright and Alf Ross have preferred the term "competence"134 and Alexy's original text employs the term "Kompetenz." In our proposal, we use the term "competence" to name corner A of the square of opposition. However, we use the terms "power" and "competence" interchangeably in the text in order to maintain the alignment with the various sources in the literature.

Robert Alexy suggests that a common element of all cases involving powers is "the alteration of the legal state of affairs by certain acts of the powerholder." ${ }^{135}$ He considers further that a central issue in the concept of competence is knowing how to differentiate actions that are the exercise of a competence from other actions that, although changing legal positions, are not considered the exercise of a competence, such as, e.g., theft, which alters legal positions but cannot be considered the exercise of a competence. ${ }^{136}$ The response is that "acts in the exercise of power are institutional acts, ${ }^{, 137}$ grounding this account of powers on Searle's account of institutional reality. The ability to create an institutional reality lies in the representation capacity of language: governments, private property,

131. The expression "norms of competence," commonly used in conjunction with "norms of conduct," does not accurately express the set of legal concepts presented in this subsection but only a part of it. For this reason, we propose using the expression "constitutive norms," which denotes more precisely the set of concepts of this subsection.

132. The term "constitutive" is applied in the same sense in law by several authors, most of them influenced by John Searle. However, Ross stated that after writing "Directive and Norms," he found the same distinction between regulative and constitutive rules in John Searle. Neil MacCormick adopts the terms "institutive" and "terminative" rules to delimit the life cycle of a legal institution. See Alf Ross, Directive and Norms (1968), at 53 n.1; Neil MacCormick, Law as Institutional Fact, in An Institutional Theory of Law: New Approaches to Legal Positrvism 49, 53-54 (Neil MacCormick \& Ota Weinberger, 1986).

133. Lars Lindahl, 112 Position and Change: A Study in Law and Logic (2012), at 194.

134. Id. at 194.

135. See Alexy, supra note 2, at 150.

136. Id. at 152.

137. AleXY, supra note 2, at 152. 
marriage, money, and universities are examples of institutions created by the declarative use of language. ${ }^{138}$ These institutional acts presuppose the existence of rules that are constitutive. ${ }^{139}$

According to Spaak, legal competence is a "hypothetical capacity" to change a legal position and cannot be confused with "permission" or "practical possibility": ${ }^{140}$

A person, $p$, has the competence in regard to a legal position, $L P$, if, and only if, there is a C-act, $a$, such that it depends for its legal effect on having been performed with an (actual or imputed) intent to bring about the relevant legal effect, and a situation, $S$, such that if $p$ in $S$ performs $a$, and thus goes about it in the right way, $p$ will, through $a$, change $L P^{141}$

The consequence of noncompliance with the conditions necessary for the exercise of the competence act causes the act to be invalid or void. For example, in most legal systems, legislating on a matter outside the competence of the legislative body is not a prohibited act but, instead, a void one.

The necessary legal effect of an intentionally exercised legal competence act in a given situation and the consequent possibility of changing the legal position (LP) induce the application of the alethic modalities to build the double scheme of constitutive norms. The first author who proposed the application of the alethic modalities to the power position was Alan Ross Anderson. ${ }^{142}$ The same approach was also suggested by Lindahl ${ }^{143}$ and recognized by L. W. Sumner. ${ }^{144}$

In our scheme, we consider not only the competence to change a legal position-with the correlative liability-but also the impossibility of changing it, which is the disability-with the correlative immunity. It is impossible to change the legal position of an agent that possesses immunity to one specific legal competence act type, as in the case of diplomatic immunity regarding certain host countries' laws. The remaining positions of the square (Figure 15) follow the same design of the square of opposition as they did in the norms of conduct.

In order to account for competences that can be defeased by an immunity in another legal relation we introduce the notion of "qualified

138. See John R. Searle, Making the Social World: The Strugture of Human Civilization (2009), at 85.

139. The terms "constitutive rules" and "regulative rules" are taken from the theory of speech acts, developed by analytic philosopher John Searle, whose contribution is known as the general theory of institutions and institutional facts. John R. Searle, Speech Acts: An Essay in the Philosophy of Language (1969); John R. Searle, The Construction of Social Reality (1995); SEARLE, supra note 138.

140. See Torben Spaak, Explicating the Concept of Legal Competence, in CONCEPTS IN LaW 67, 74 (Jaap C. Hage \& Dietmar von der Pfordten eds., 2009).

141. Id. at 81 .

142. See Allan Ross Anderson, Logic, Norms and Roles, 4 Ratio 47 (1962).

143. LiNDAHL, supra note 133, at 207.

144. Sumner, supra note 85 , at 28. 
(Necessary to change LP)

$\frac{\text { Competence }}{\text { Liability }}$
(Impossible to change LP)

$$
\frac{\text { Disability }}{\text { Immunity }}
$$

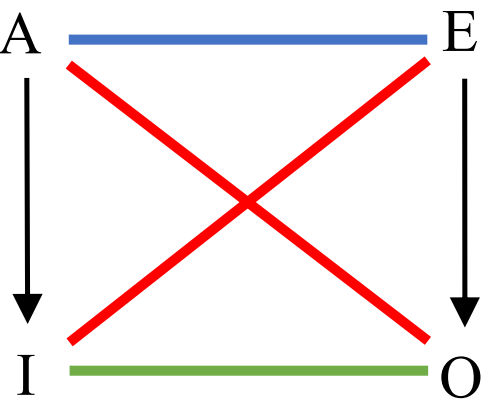

(Possible to change LP)

No disability

(Not necessary to change LP)

No immunity

$\frac{\text { No competence }}{\text { No liability }}$

Figure 15 Constitutive Norms in the Square of Opposition

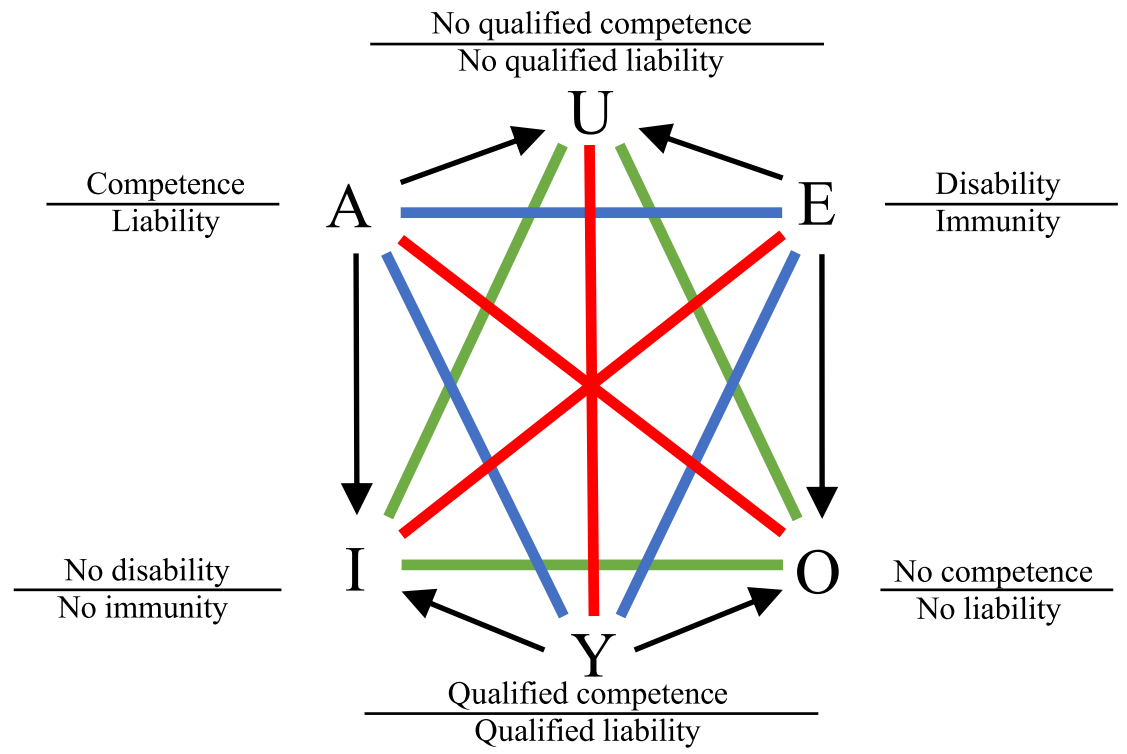

Figure 16 Hexagon for Constitutive Norms

competence" in the triangle of possibilities (Figure 16). In this case, one specific attempt to exercise a qualified competence act may be unsuccessful if the other agent has immunity in relation to this act type. Since, in most instances, the rules of competence and immunity are expressed in a generic and independent way, it is impossible to know in advance, for a certain factual situation, whether immunities against a certain competence act 


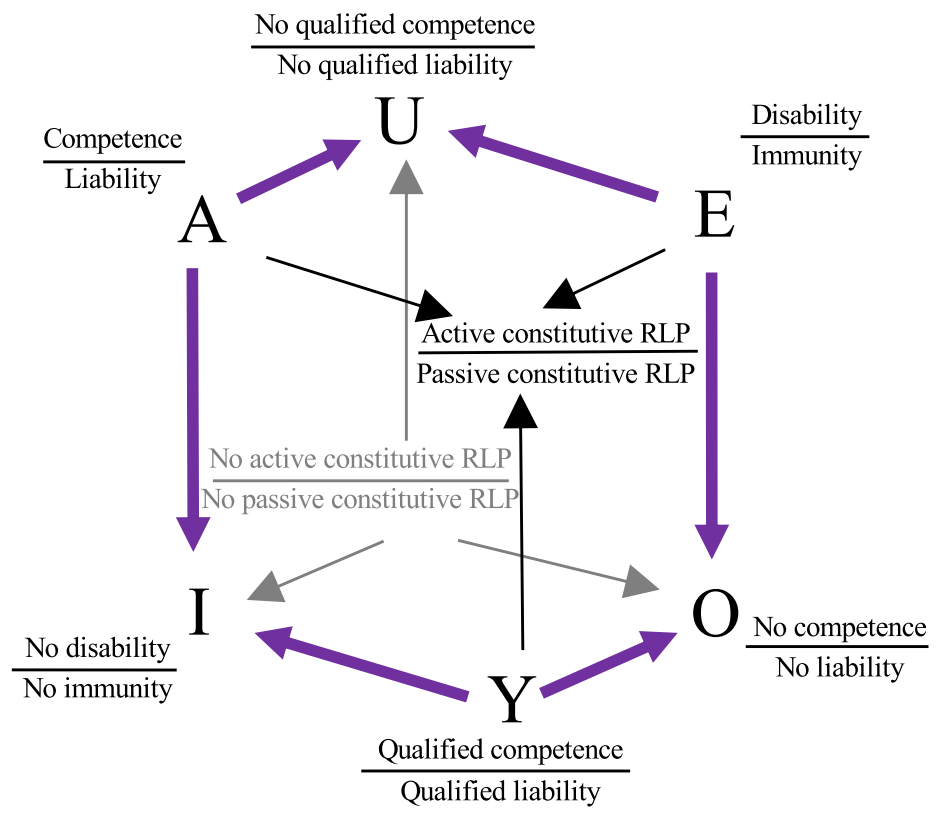

Figure 17 Cube of Constitutive Positions

exist. Therefore, in a specific factual situation, legal effects may be created by an institutional fact derived from a competence (corner A) or may be derived from a qualified competence (corner Y) if the other agent does not have immunity. Tax collection is an example of a qualified competence, since certain entities, such as embassies, may have immunity to certain taxes. Competence may become qualified competence if the legal system introduces immunities against this competence act type for a portion of the target agents. Conversely, a qualified competence may become a competence if the existing immunities are revoked. Note the correspondence with the alethic modalities; in the case of (absolute) "competence," there is no provision for immunities in the normative system, and hence attempts to exercise competence will necessarily constitute an institutional act with legal effect. In the case of a disability, there is impossibility of changing legal position, hence no constitution of an institutional act. In the case of qualified competence, legal effect is contingent.

By also considering the normative system open, we include the fourth alternative, which is the lack of a normative status concerning change in legal position. This forms a logical cube for constitutive positions (Figure 17) with an embedded weak hexagon as shown in Figure 16. The position in which there is neither competence nor qualified competence nor disability (at the far vertex behind the cube) is one in which there is a weak sense of disability and a weak sense of immunity. 

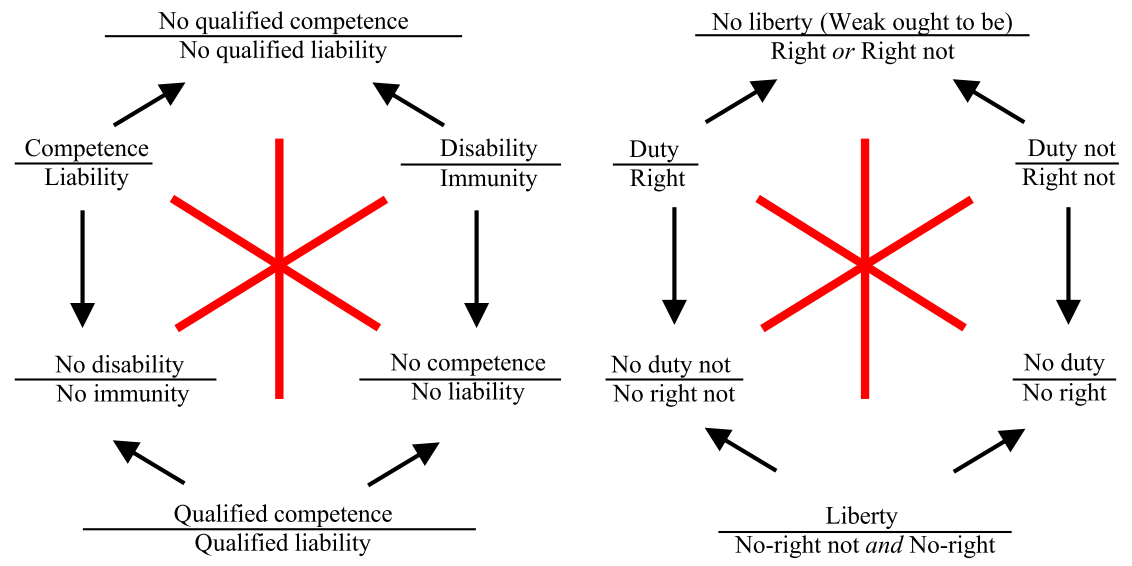

Figure 18 Hexagons of Fundamental Legal Concepts

\section{Hexagons of Fundamental Legal Concepts}

This last subsection of this section of the article presents the proposed hexagons in only one figure and compares certain aspects of these hexagons.

As we have seen, the constitutive norms establish the legal relations that are regulated by norms of conduct; thus, constitutive norms precede norms of conduct in time. As such, we have drawn the hexagon of constitutive norms before the hexagon for norms of conduct in Figure 18. By reversing the original placement proposed by Hohfeld (Figure 1), we have drawn a cleaner diagram, in which we have excluded the contrary and subcontrary relations. We highlight that our goal here is more one of conceptual clarification than one of terminological systematization. Hence, following the motto that "what is important is not the words, but the ideas which they represent," ${ }^{145}$ we advocate that terminological debates can be accommodated when (and only when) these concepts and their relations are sufficiently clarified.

While the hexagon of norms of conduct presents the positions of agents involved in an already established legal relation, the hexagon of constitutive norms presents the positions of agents according to the legal effects of acts that could create, modify, or extinguish (other) legal relations. The nucleus of the former is to act (or not to act) with causal consequences, and the nucleus of the latter is to bring legal effects (or not) with constitutive grounds. The distinction between causal and constitutive forms of action is explained by Searle contrasting the actions of fire the gun and place a vote respectively. ${ }^{146}$

145. See Reginald Walter Michael Dias, Jurisprudence (1970), at 270.

146. "Human actions also have some very special features deriving from the fact that typically I do not just perform a simple action like raising my arm, but I do something by way of or by 
It is important to note that the constitutive act is manifested by some causal act, such as uttering, "I now pronounce you married," or by the apposition of a signature in a paper in a given situation, as in this explanation:

Consider, for example, a national governmental body with the ability (the putative power) to establish international treaties. By signing a certain document, the governmental body does not cause the establishment of the relevant international treaty. Rather, the act, in the relevant context (along with other acts such as the signing of the document by other appropriately authorized parties), is or constitutes the establishment of the treaty. Of course, the actual writing process is (at some level) a physical, causal process; but this process (or rather the end stage of it), which more or less anyone who can write can reproduce, non-casually [sic] constitutes the establishment of the treaty in the context in question. ${ }^{147}$

The norm that prescribes a sanction in the case of a norms-of-conduct violation is constitutive in essence, as in the case of a fine for party conduct that breaches a contractual clause, or a penalty created for a person who has committed a crime. The fine is created according to the contractual clauses, and the penalty needs to be declared by the proper authority.

\section{CONCLUSION}

The importance of the study of legal relations and the legal positions established by those relations may be observed in the following statement: "Legal relations are the units of legal reasoning." 148 According to Kocourek, legal relations are to lawyers what atoms are to chemists. ${ }^{149}$ Following this analogy, we can say that the eight fundamental legal concepts proposed by Hohfeld form a scheme of legal positions that is complemented via this study as shown in Figure 18. When designing the periodic table in chemistry, Dmitri Mendeleev (1834-1907) reserved positions for some elements that were not yet known, but the logic employed indicated their existence, and they were indeed discovered by subsequent researchers. Similarly, in casting the light of the theory of opposition on Hohfeld's work, as well as by considering the proposals of several authors advancing that original proposal, we were able to provide a fuller analysis of the various legal positions and their relations.

means of doing something else .... So, for example, I fire the gun by means of pulling the trigger and I vote in the committee meeting by way of raising my arm. Pulling the trigger causes the gun to fire, but raising my arm does not cause the vote to take place; it just constitutes voting. I call these two types of inner structure of action the casual [sic] by-means-of relation and the constitutive by-way-of relation." SEARLE, supra note 138, at 51.

147. Hansson Wahlberg, Causal Powers and Social Ontology, 197 SynTHeSE 1370 (2020).

148. Albert Kocourek, Jural Relations (1928), at 77.

149. Id. at 77. 
Applying the theory of opposition to fundamental legal concepts breaks new ground in the following aspects:

a) It confirms the inadequacy of replacing the term "privilege" with the term "liberty"; ${ }^{150}$

b) It harmonizes the original contribution of Hohfeld with the "liberty" and "no liberty" concepts;

c) It shows that "liberty" has the same standing as "duty" and "duty not" in an open conflict-free normative system; ${ }^{151}$

d) It shows the three-dimensional structure (a cube) that is required in an open normative system, beyond what can be shown with the standard deontic hexagon;

e) It shows, in a clear and symmetrical manner, the opposition (contradiction) between strong positions and their weak counterparts, including the contradiction between (strong) "liberty" and "no liberty" (or weak ought to be);

f) It positions the various opposition analyses in the literature according to their stance with respect to conflict-freedom and completeness assumptions, charting the territory in the application of opposition theory to Hohfeld's concepts;

g) It presents a dual scheme for constitutive norms, similar to the dual scheme of the norms of conduct created by Fitch; ${ }^{152}$

h) It gives a reason for the precedence of constitutive norms over norms of conduct;

i) It offers a solution that distinguishes the concept of "competence" from "qualified competence."

Max Radin considers that in considering analysis proposed by Hohfeld, "we are dealing with an attempt at a legal algebra or a geometry." 153 The present article participates in such an attempt by using a geometric shape to identify the relata that compose the various intersubjective legal relations.

150. It is interesting to note that this problem seems to remain unnoticed by most modern authors. As we have seen, the solution, based on logic, has been offered for decades. For example, Barker notes that privileges are "often referred to by more modern writers as "liberties." Barker is correct in stating this reality, but he fails to recognize the logical error of the original scheme. See Barker, supra note 6 , at 589.

151. See Alchourrón, supra note 103.

152. Fitch, supra note 11.

153. Max Radin, A Restatement of Hohfeld, 51 Harv. L. Rev. 1141, 1147 (1938). 